Supplement of The Cryosphere Discuss., 9, 115-140, 2015

http://www.the-cryosphere-discuss.net/9/115/2015/

doi:10.5194/tcd-9-115-2015-supplement

(C) Author(s) 2015. CC Attribution 3.0 License.

(c) (i)

Supplement of

\title{
Future projections of the climate and surface mass balance of Svalbard with the regional climate model MAR
}

\section{Lang et al.}

Correspondence to: C. Lang (charlotte.lang@ulg.ac.be) 


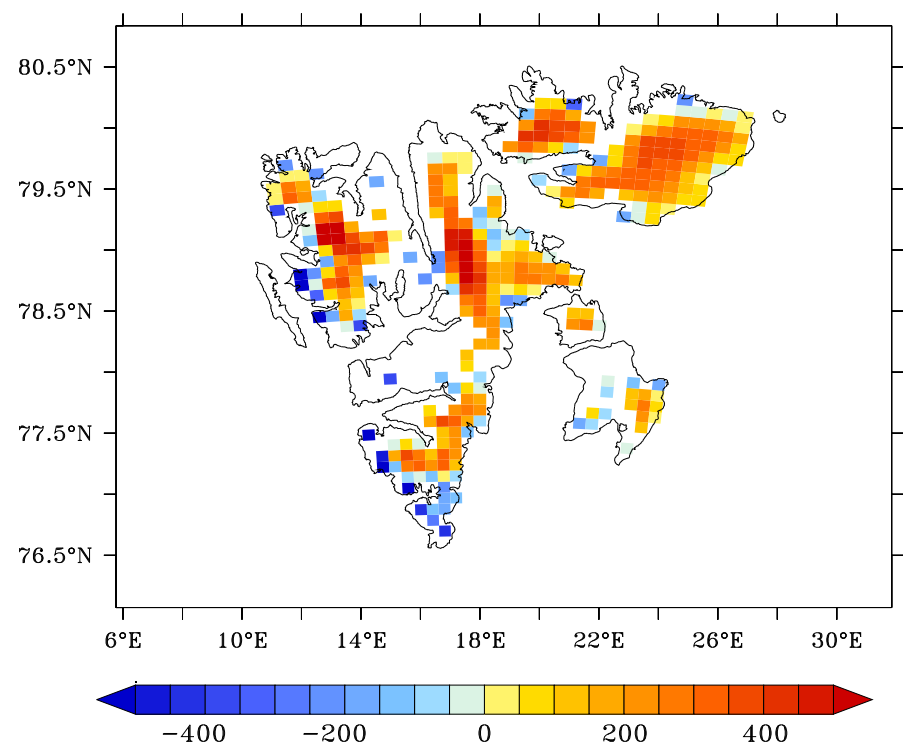

Fig. 1. 1980-2005 reference mean annual SMB (mmw.e. $\mathrm{yr}^{-1}$ ) simulated by MAR histo from Lang et al. (2014). 

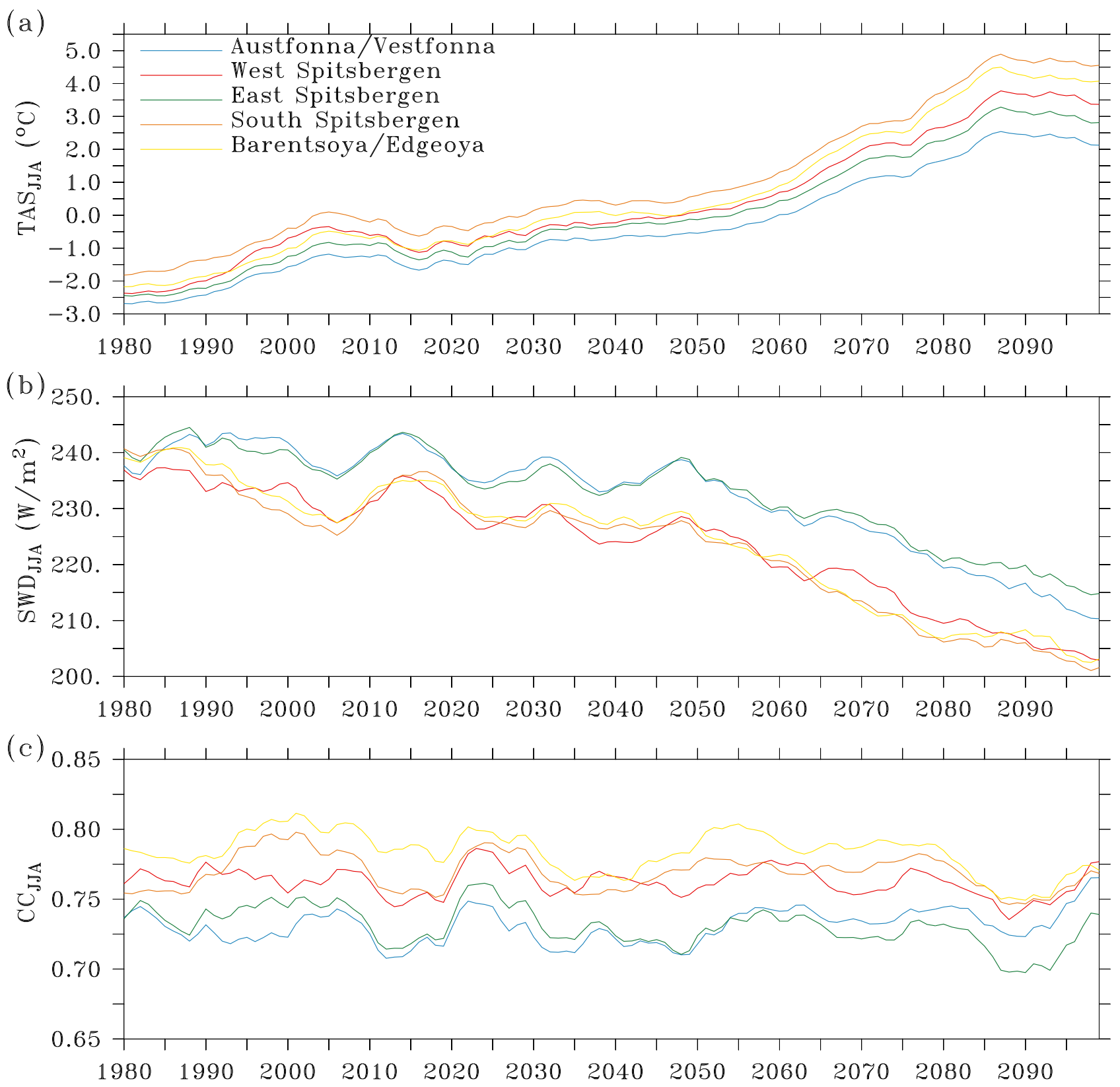

Fig. 2. (a) Near-surface JJA temperature $\left(\mathrm{TAS}_{\mathrm{JJA}}\right)$ 10-year running mean $\left({ }^{\circ} \mathrm{C}\right)$ for the 5 different regions shown in Figure 3 as simulated by MAR forced by the MIROC5 based historical scenario over 1980-2005 and RCP8.5 afterwards. (b) Same as (a) but for the JJA net solar radiation $\left(\mathrm{SWD}_{\mathrm{JJA}}, \mathrm{Wm}^{-2}\right)$. (c) Same as (a) but for the cloud cover $\left(\mathrm{CC}_{\mathrm{JJA}}\right.$, going from 0 for completely clear sky to 1 for completely overcast). 

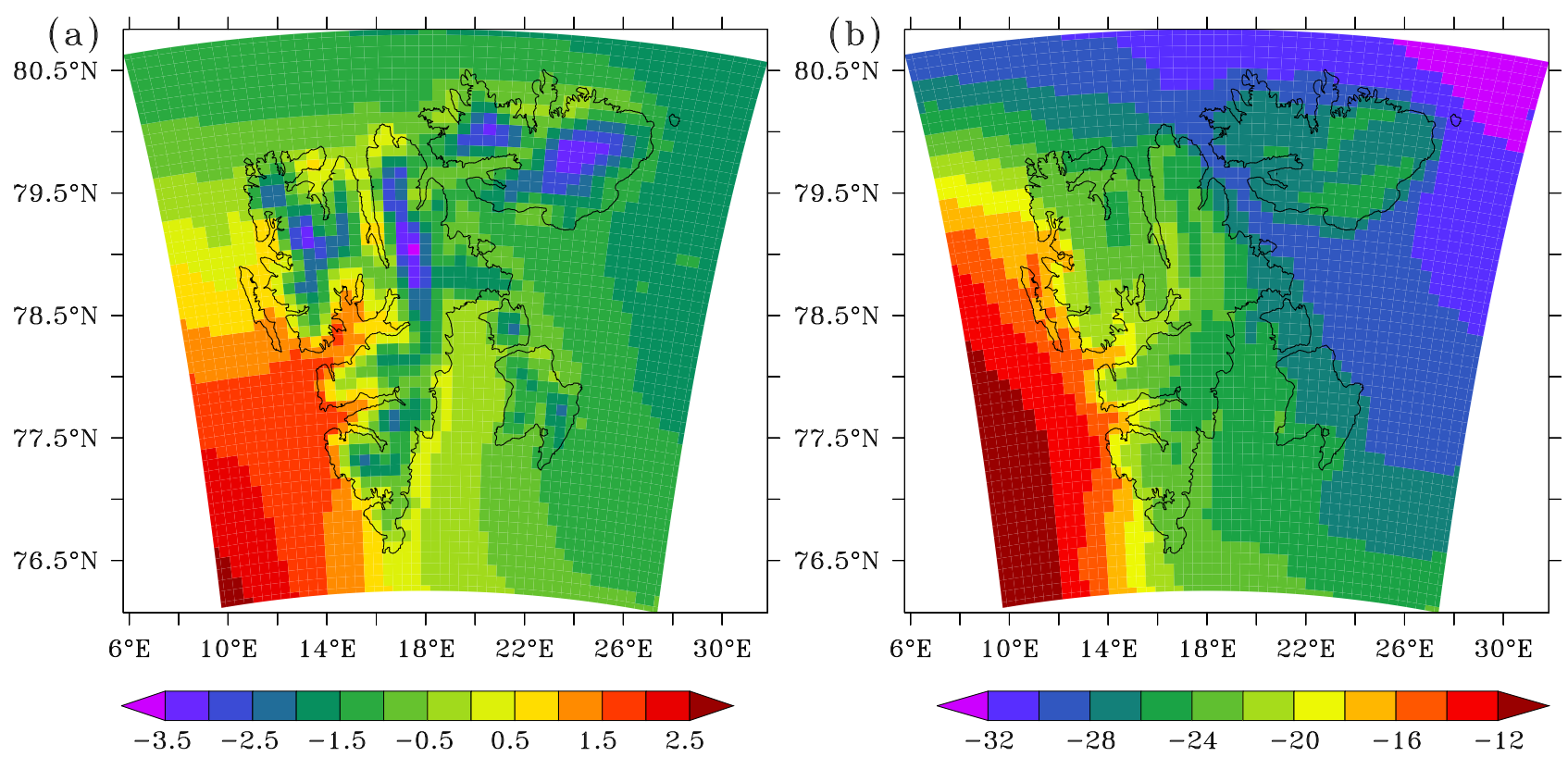

Fig. 3. (a) 1980-2005 mean summer (JJA) near-surface temperature $\left({ }^{\circ} \mathrm{C}\right)$. (b) Same as (a) but for winter (DJF).
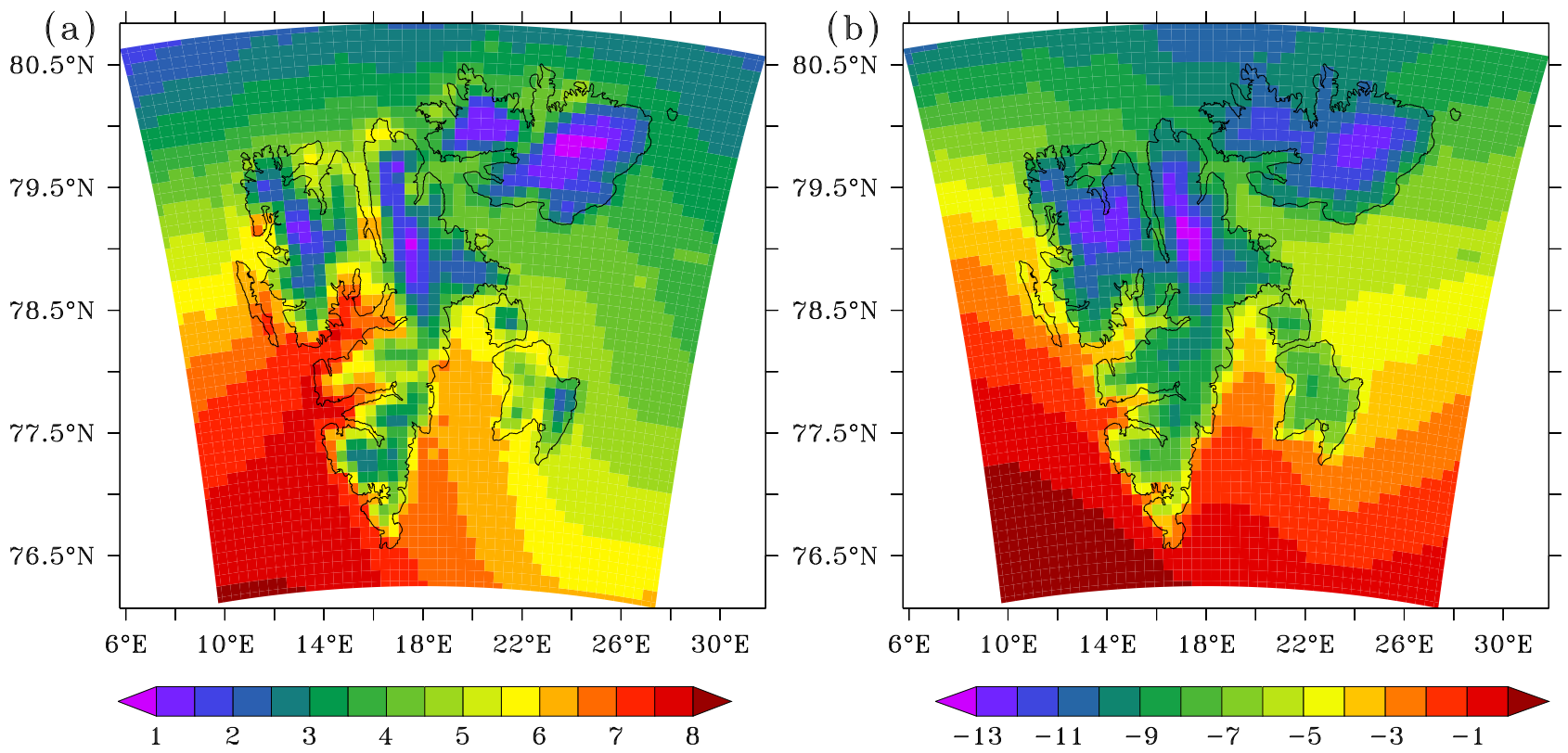

Fig. 4. (a) Same as Figure S3a but for 2070-2099. (b) Same as (a) but for winter (DJF). 


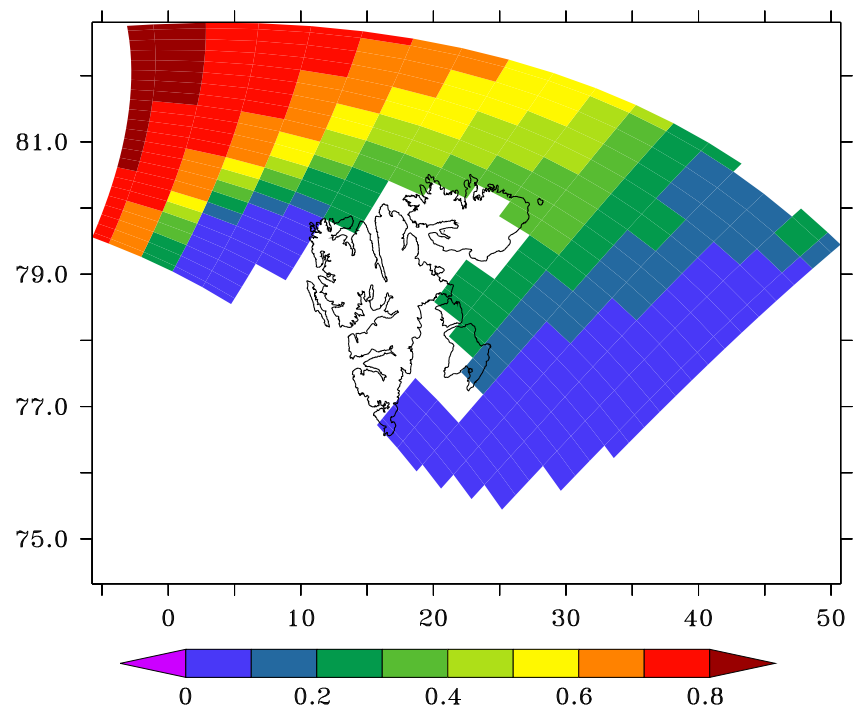

Fig. 5. 2070-2099 mean winter (DJF) sea-ice cover from MIROC5. 
Table 1. Relative contribution of the energy balance components to the NET anomaly over 2080-2099 with respect to the 1980-2005 mean.

\begin{tabular}{lc}
\hline $\begin{array}{l}\text { E balance } \\
\text { component }\end{array}$ & $\begin{array}{c}\text { \% of NET anomaly } \\
(2080-2099)\end{array}$ \\
\hline SWDnet & 33 \\
SWDalb & 49 \\
SWDswd & -7.5 \\
SHF & 24 \\
LHF & 22 \\
LWnet & 21 \\
\hline
\end{tabular}

